\title{
Hepatitis A virus infection associated with cannabis use
}

\author{
C Sikora ${ }^{1,2 \star}$, G Tipples ${ }^{2,3}$, X-L Pang ${ }^{2,3}$, A Andonov ${ }^{4,5}$
}

\begin{abstract}
We identified a case of acute Hepatitis A virus (HAV) infection linked to cannabis use. The local Public Health department received report of a man in his mid-20s with a classic presentation of hepatitis - jaundice, abdominal pain, vomiting, general malaise, and dark urine - as well as elevated serum aminotransferase levels and a positive anti-HAV IgM. Upon questioning, he reported no contact with ill individuals, or travel outside his metropolitan area. His exclusive source of water was the local municipal supply. He reported consuming mainly pre-packaged lower risk foods from large chain-style supermarket stores and eating at several local restaurants. While administering the questionnaire, the investigator identified that the patient smoked cannabis. Upon request, the patient agreed to provide a sample of cannabis for testing purposes. A viral elution of fresh cannabis leaves was completed. The sequences derived from the patient's serum sample and the eluate from the cannabis leaves were identical, but did not match any other HAV sub-genotype $1 \mathrm{~B}$ sequences from Canadian isolates within the National Microbiology Laboratory database. Hepatitis A virus can survive $>60$ days when dried and kept at room temperature and low humidity; HAV can remain infectious in water at room temperature for 300 days. It cannot be concluded with certainty that the cannabis was the source of the hepatitis A; however, as other sources were excluded, or were of lesser probability, the association of cannabis with his disease acquisition remains strong.
\end{abstract}

\author{
Affiliations \\ ${ }^{1}$ Alberta Health Services, \\ Edmonton, $A B$ \\ ${ }^{2}$ University of Alberta, Edmonton, \\ $A B$ \\ ${ }^{3}$ Provincial Laboratory for Public \\ Health, Alberta Health Services, \\ Edmonton, $A B$ \\ ${ }^{4}$ National Microbiology \\ Laboratory, Public Health Agency \\ of Canada, Winnipeg, MB \\ ${ }^{5}$ University of Manitoba, \\ Winnipeg, MB
} *Correspondence: christopher.
sikora@ahs.ca

Suggested citation: Sikora C, Tipples G, Pang X-L, Andonov A. Hepatitis A virus infection associated with cannabis use. Can Commun Dis Rep. 2017;43(11):245-6. https://doi.org/10.14745/ccdr.v43i11a07

The medical literature reports that cannabis can be contaminated by bacteria, mold, and chemicals such as pesticides, lead, ammonia, and formaldehyde (1). We identified a case of acute hepatitis $A$ virus (HAV) infection linked to cannabis use. The local Public Health department received report of a patient with a positive anti-HAV IgM. The patient was a man in his mid- 20s with a classic clinical presentation of hepatitis - jaundice, abdominal pain, vomiting, general malaise, and dark urine - and elevated serum aminotransferase levels (ALT, AST). He reported no contact with ill individuals, or travel outside of the local urban metropolitan area in the previous two years. Subsequent blood testing identified the presence of HAV genotype 1B.

A thorough food history was completed (2). His exclusive source of water was the local municipal supply. Grocery shopping was done at several large chain-style supermarket stores. He reported eating at several local restaurants, and had consumed mainly pre-packaged lower risk foods. No specific exposures or high-risk contacts were identified. While administering the questionnaire, the investigator identified that the patient frequently smoked cannabis during the previous several months. Upon request, the patient agreed to provide a sample of cannabis for testing purposes. A viral elution of fresh cannabis leaves was completed followed by ultracentrifugation to concentrate the eluate, which was done as previously described (3). Hepatitis A virus was extracted by the EasyMag platform (NucliSENS® easyMAG, bioMérieux, Montreal), and amplified by reverse transcription polymerase chain reaction (RT-PCR) (4).
The sequences derived from the patient's serum sample and the eluate from the cannabis leaves were identical. These two sequences were unique and did not match any other HAV subgenotype 1B sequences from Canadian isolates within our database (Figure 1).

There are several reports in the literature citing cannabis use as a risk for acquiring hepatitis $A(5,6)$, although simultaneous parenteral drug use and sharing of potentially contaminated paraphernalia have been suggested as a mechanism of transmission. Smoking or handling of fecally-contaminated cannabis has also been implicated in the transmission of salmonellosis (7).

The presentation of this case of locally acquired hepatitis A was unusual. The Edmonton area (population approximately 1.2 million) has approximately 6-28 HAV cases per year, and all but one or two are associated with travel to endemic areas (8). In this case, there were no genetic linkages with other known cases, leading local public health to suspect an unrecognized reservoir. It appears the patient may have been infected by ingesting small particles of cannabis from a hand-rolled cigarette.

Hepatitis A virus is exceptionally sturdy and can survive for a prolonged period of time (> 60 days) when dried and kept at room temperature and low humidity (9). Alternatively an HAV-contaminated water source used for the cannabis grow-op 
Figure 1: Maximum likelihood phylogenetic tree of the VP1-P2A junction (nucleotides 2903 to 3275 , according to the reference strain $\mathrm{HM}-175$ ) showing the relationship between Canadian HAV 1B isolates

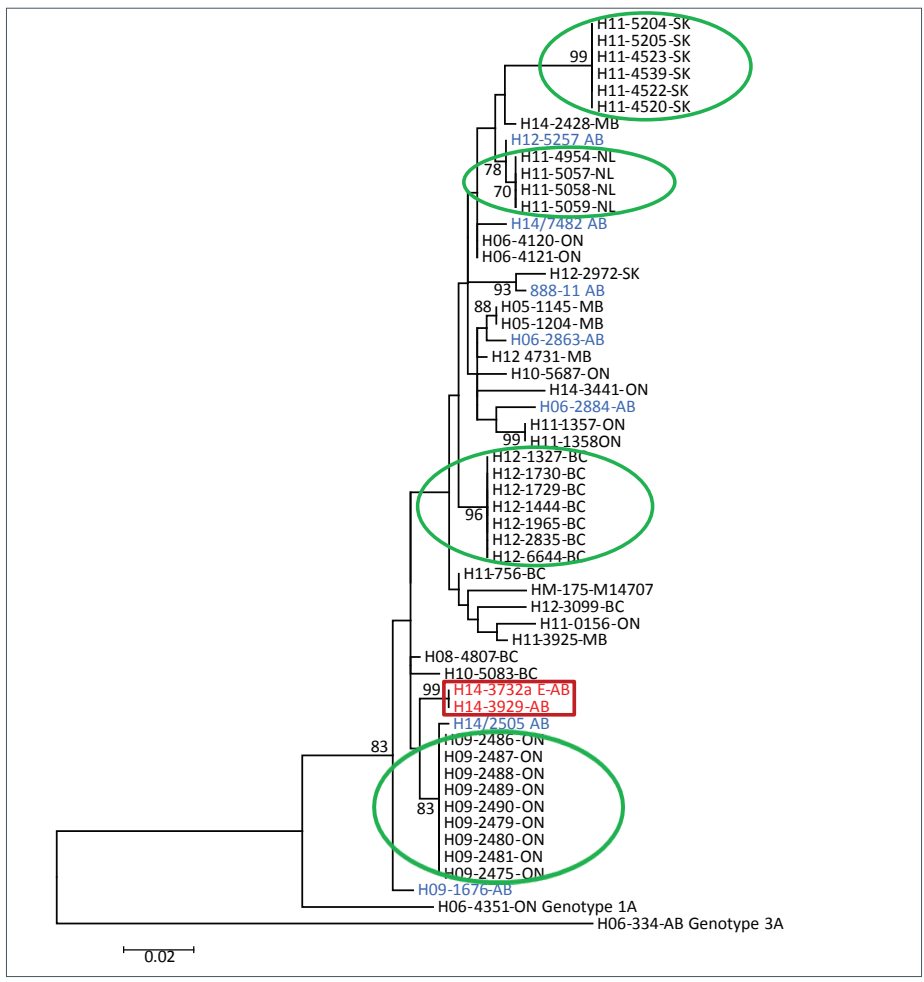

Legend: The reference HAV 1B strain HM-175-M14707 is in bold font. Numbers indicate the reproducibility after 1,000 bootstraps, and only bootstraps values higher than $70 \%$ are shown. Genotypes $1 \mathrm{~A}$ and $3 \mathrm{~A}$ are included as outliers. The scale bar indicates $2 \%$ sequence diversity. Patient and cannabis leaves eluate isolates (red font) are compared to other $1 \mathrm{~B}$ isolates from the same (blue font) or other provinces (black font). Epidemiologically linked cases from different outbreak clusters illustrating the genomic sequence identity are encircled

could have contributed to the infection; HAV can remain infectious in water at room temperature for 300 days (10).

It cannot be concluded with certainty that the cannabis was the source of the hepatitis A; however, as other sources were excluded, or were of lesser probability, the association of cannabis with his disease acquisition remains strong.

Given the variable conditions in which cannabis is produced, it is unknown what infectious disease risk may be present. Monitoring and testing of cannabis may be needed for the purposes of safety and quality.

\section{References}

1. Guidance for State Medical Cannabis Testing Programs http://www.aphl.org/aboutAPHL/publications/Documents/ EH-Guide-State-Med-Cannabis-052016.pdf\#search=cannabis [Consulté le 27 octobre 2017]

2. Public Health Agency of Canada's Hepatitis A HypothesisGenerating Questionnaire. http://www.health.alberta.ca/ documents/PHAC-Hepatitis-A-Hypothesis-GeneratingQuestionnaire-2013.pdf [Consulté le 27 octobre 2017]

3. Sun Y, Laird DT, Shieh YC. Temperature-dependent survival of hepatitis A virus during storage of contaminated onions. Appl Environ Microbiol 2012 Jul;78(14):4976-83. DOI (http:// dx.doi.org/10.1128/AEM.00402-12). PubMed (https://www. ncbi.nlm.nih.gov/entrez/query.fcgi?cmd=Retrieve\&db=PubM ed\&list_uids=22544253\&dopt=Abstract).

4. Swinkels HM, Kuo M, Embree G, Andonov A, Henry B, Buxton JA; Fraser Health Environmental Health Investigation Team. Hepatitis A outbreak in British Columbia,

Canada: the roles of established surveillance, consumer loyalty cards and collaboration, February to May 2012. Euro Surveill 2014 May;19(18):20792. DOI (http://dx.doi. org/10.2807/1560-7917.ES2014.19.18.20792). PubMed (https://www.ncbi.nlm.nih.gov/entrez/query.fcgi?cmd=Retrie ve\&db=PubMed\&list_uids=24832119\&dopt=Abstract).

5. Harkess J, Gildon B, Istre GR. Outbreaks of hepatitis A among illicit drug users, Oklahoma, 1984-87. Am J Public Health 1989 Apr;79(4):463-6. DOI (http://dx.doi. org/10.2105/AJPH.79.4.463). PubMed (https://www.ncbi. nlm.nih.gov/pubmed/2929804?dopt=Abstract).

6. Shaw DD, Whiteman DC, Merritt AD, el-Saadi DM, Stafford RJ, Heel K, SMith GA. Hepatitis A outbreaks among illicit drug users and their contacts in Queensland, 1997. Med J Aust 1999 Jun;170(12):584-7. PubMed (https://www.ncbi. $\mathrm{nlm}$.nih.gov/entrez/query.fcgi?cmd=Retrieve \&db=PubMed\&l ist_uids $=10416427 \&$ dopt $=$ Abstract).

7. Taylor DN, Wachsmuth IK, Shangkuan YH, Schmidt EV, Barrett TJ, Schrader JS et al. Salmonellosis associated with marijuana: a multistate outbreak traced by plasmid fingerprinting. N Engl J Med 1982 May;306(21):1249-53. DOI (http://dx.doi.org/10.1056/ NEJM198205273062101).PubMed (https://www.ncbi.nlm. nih.gov/entrez/query.fcgi?cmd=Retrieve \&db=PubMed\&li st_uids=7070444\&dopt=Abstract).

8. Interactive Health Data Application. http://www.ahw.gov. ab.ca/IHDA_Retrieval/

9. Abad FX, Pintó RM, Bosch A. Survival of enteric viruses on environmental fomites. Appl Environ Microbiol 1994 Oct;60(10):3704-10. PubMed (https://www.ncbi.nlm.nih. gov/entrez/query.fcgi?cmd=Retrieve\&db=PubMed\&lis t_uids $=7986043 \&$ dopt $=$ Abstract)

10. Biziagos E, Passagot J, Crance JM, Deloince R. Long-term survival of hepatitis A virus and poliovirus type 1 in mineral water. Appl Environ Microbiol 1988 Nov;54(11):2705-10. PubMed (https://www.ncbi.nlm.nih. gov/entrez/query.fcgi?cmd=Retrieve\&db=PubMed\&lis t_uids=2850763\&dopt=Abstract). 